\title{
Resposta de cultivares de arroz a doses de nitrogênio e do regulador de crescimento cloreto de clormequat
}

\author{
Salatiér Buzetti( ${ }^{(1)}$, Graciela Cristina Bazanini(1), José Guilherme de Freitas ${ }^{(2)}$, Marcelo Andreotti(1), \\ Orivaldo Arf ${ }^{(3)}$, Marco Eustáquio de Sá( ${ }^{(3)}$ e Flávia de Andrade Meira ${ }^{(1)}$
}

\begin{abstract}
(1)Universidade Estadual Paulista (Unesp), Fac. de Engenharia de Ilha Solteira, Dep. de Fitossanidade, Engenharia Rural e Solos, Caixa Postal 31, CEP 15385-000 Ilha Solteira, SP. E-mail: sbuzetti@agr.feis.unesp.br, bazanini@aluno.feis.unesp.br, dreotti@agr.feis.unesp.br, meira@aluno.feis.unesp.br (2)|nstituto Agronômico, CaixaPostal 28, CEP 13001-970 Campinas, SP. E-mail: freitas@iac.sp.gov.br (3)Unesp, Fac. de Engenharia de Ilha Solteira, Dep. de Fitotecnia, Tecnologia de Alimentos e Sócio-Economia. E-mail: arf@agr.feis.unesp.br, mesa@agr.feis.inesp.br
\end{abstract}

Resumo - O objetivo deste trabalho foi avaliar os efeitos de doses de nitrogênio (0, 50, 100 e $\left.150 \mathrm{~kg} \mathrm{ha}^{-1}\right)$ e do regulador de crescimento cloreto de clormequat (0, 1 e $\left.2 \mathrm{~L} \mathrm{ha}^{-1}\right)$, em algumas características agronômicas de cultivares de arroz IAC 201 e IAC 202. O delineamento experimental foi o de blocos ao acaso, com quatro repetições. O N foi aplicado em cobertura, no estádio da diferenciação floral, e o regulador de crescimento foi aplicado parceladamente, aos 20 e 30 dias após a emergência das plântulas de arroz (perfilhamento). Na safra 2001/2002, houve efeito significativo de $\mathrm{N}$ para altura de plantas, comprimento da panícula, espiguetas por panícula, massa de 100 grãos e produtividade de grãos. Houve efeito do regulador de crescimento sobre o comprimento da panícula e espiguetas por panícula. A maior produtividade foi a da cultivar IAC 202. Na safra 2002/2003, houve efeito de $\mathrm{N}$ para altura de plantas, massa de 100 grãos, fertilidade das espiguetas e produtividade de grãos. O regulador de crescimento não exerceu efeito nas características testadas, e a cultivar IAC 202 foi novamente a mais produtiva.

Termos para indexação: Oryza sativa, componentes de produtividade, irrigação por aspersão.

\section{Response of rice cultivars to nitrogen and growth regulator chlormequat chloride}

\begin{abstract}
The objective of this work was to evaluate $\mathrm{N}$ rates $\left(0,50,100\right.$ and $\left.150 \mathrm{~kg} \mathrm{ha}^{-1}\right)$ and the growth regulator chlormequat chloride effect $\left(0,1\right.$ e $\left.2 \mathrm{~L} \mathrm{ha}^{-1}\right)$ on some agronomic characteristics of rice cultivars IAC 201 and IAC 202. The experimental design was a randomized block with four replicates. Nitrogen was applied as sidedressing at flower differentiation and the growth regulator was split in two times and applied at 20 and 30 days after seedlings emergency (tillering). In the harvests of 2001/2002, there was no significant effect of $\mathrm{N}$ rates on plant height, panicle length, spikelet per panicle, 100-grain mass and grain yield. The growth regulator rates were significant for panicle length and spikelet per panicle. IAC 202 presented higher grain yield. In the harvest of 2002/2003 there was no effect of N rates on plant height, spikelet fertility, 100-grain mass and grain yield. The growth regulator rates had no effect on tested characteristics, and IAC 202 cultivar presented higher grain yield.

Index terms: Oryza sativa, productivity components, sprinkler irrigation.
\end{abstract}

\section{Introdução}

A cultura do arroz no Brasil ocupa posição de destaque do ponto de vista econômico e social, pois está presente na dieta da maioria dos brasileiros. A área cultivada na safra 2003/2004 foi de 3,57 milhões de hectares com produção próxima a 12 milhões de toneladas. O consumo foi estimado em 12,7 milhões de toneladas (Fao, 2004). O Brasil ocupa o 10ํ lugar em produção mundial e tem um consumo per capita de $42 \mathrm{~kg}$ por habitante por ano.

A produtividade final da cultura do arroz depende da cultivar utilizada, da quantidade de insumos e das técnicas de manejo empregadas. Dos nutrientes essenciais às plantas, o $\mathrm{N}$ está entre os requeridos em maior quantidade e é, por isso, considerado um importante fator para determinar o potencial de produtividade. A dose de $\mathrm{N}$ a ser utilizada baseia-se 
na estatura das plantas e na fertilidade do solo. O N estimula o crescimento do sistema radicular do arroz, e conseqüentemente, favorece o perfilhamento, aumenta o número de espiguetas por panícula e a porcentagem de proteína nos grãos. A adubação nitrogenada aumenta o número de colmos e panículas por área (Campello Junior, 1985) e o número de espiguetas (Fornasieri Filho \& Fornasieri, 1993). A reposta à adubação nitrogenada é variável: pode apresentar incremento de produtividade com doses superiores a $100 \mathrm{~kg} \mathrm{ha}^{-1}$ de N (Stone et al., 1999), ou não mostrar influência nem mesmo nos componentes da produtividade e rendimento industrial de grãos (Arf et al., 2003).

A crescente utilização de cultivares de alto potencial produtivo tem implicado no uso mais freqüente de insumos, entre os quais o N. No entanto, a utilização de doses cada vez mais elevadas deste nutriente, para aumentar a produtividade, acarreta em elevado desenvolvimento vegetativo, o que causa acamamento de plantas e interfere negativamente na produtividade e na qualidade dos grãos. O problema de acamamento pode ser minimizado com o uso de cultivares resistentes, o que vem ocorrendo, e com o uso de reguladores de crescimento, que além de diminuírem o tamanho da planta proporcionam um melhor aproveitamento de nutrientes, em razão das alterações fisiológicas que exercem sobre a planta.

Os reguladores vegetais, neste caso retardantes vegetais, são compostos sintéticos utilizados para reduzir o crescimento longitudinal indesejável da parte aérea das plantas, sem diminuição da produtividade (Rademacher, 2000). A maioria dos retardantes vegetais age por inibição da biossíntese de giberelinas, hormônios que entre outras ações promove alongamento celular (Davies, 1995). Os diferentes tipos de retardantes vegetais inibem a rota comum de síntese de todos os ácidos giberélicos dos vegetais superiores, em diferentes locais; até 1995, foram isolados mais de 126 giberelinas (Arteca, 1995). O produto inibe a biossíntese do ácido giberélico, o que causa a redução do crescimento, em razão da menor elongação celular (Lamas, 2001).

O momento e os modos de aplicação do regulador de crescimento têm sido alvo de pesquisa, pois seus efeitos sobre a produção demonstram-se inconsistentes, verificando-se aumento de produtividade em alguns casos e, em outros, diminuição. Estas características são preocupantes, quando se utilizam essas cultivares sob alta tecnologia, mais especificamente o cultivo irrigado por aspersão, em que o produtor, em busca de maior rentabilidade, emprega maiores doses de fertilizantes, principalmente os nitrogenados, uma vez que não há limitação hídrica para a planta. Dessa forma, acreditase haver um efeito entre o $\mathrm{N}$ e a disponibilidade hídrica, que acarreta acamamento parcial ou total das plantas (Arf, 1993). Assim, tornou-se evidente a necessidade de obtenção de cultivares que apresentem porte baixo, resistência ao acamamento, respondam à adubação nitrogenada, com melhor carreamento dos fotoassimilados para os grãos, além de apresentar característica de grão tipo agulhinha, exigida pelo mercado. Como a altura da planta se relaciona com o índice de acamamento, em cultivares sensíveis a este, o uso de reguladores de crescimento pode minimizar tal índice.

O objetivo desse trabalho foi avaliar os efeitos de doses de $\mathrm{N}$ e de regulador de crescimento cloreto de clormequat em algumas características agronômicas e na produtividade de cultivares de arroz IAC 201 e IAC 202.

\section{Material e Métodos}

O trabalho foi realizado em área experimental da Faculdade de Engenharia de Ilha Solteira, Unesp, em Selvíria, MS (20²2"S e 5122"W, com altitude de 335 m). A precipitação, temperatura e umidade relativa médias anuais são de aproximadamente $1.370 \mathrm{~mm}, 23,5^{\circ} \mathrm{C}$ e 70 a $80 \%$, respectivamente. O solo do local é classificado como Latossolo Vermelho distroférrico típico (Embrapa, 1999), anteriormente ocupado por vegetação de cerrado, e apresenta as seguintes características químicas na camada $0-20 \mathrm{~cm}$, antes da instalação do experimento, segundo Raij \& Quaggio (1983): $\mathrm{pH}\left(\mathrm{CaCl}_{2}\right)$ 5,9; $27 \mathrm{~g} \mathrm{dm}^{-3}$ de $\mathrm{MO} ; 31 \mathrm{mg} \mathrm{dm}^{-3}$ de P (resina); $6 \mathrm{mmol}_{\mathrm{C}} \mathrm{dm}^{-3}$ de $\mathrm{K} ; 49 \mathrm{mmol}_{\mathrm{C}} \mathrm{dm}^{-3}$ de Ca; $21 \mathrm{mmol}_{\mathrm{C}} \mathrm{dm}^{-3} \mathrm{de} \mathrm{Mg} ; 20 \mathrm{mmol}_{\mathrm{c}} \mathrm{dm}^{-3} \mathrm{de} \mathrm{H}+\mathrm{Al} ; \mathrm{V}, 79 \%$.

O preparo do solo foi realizado com uma aração e duas gradagens, com posterior semeadura manual das cultivares de arroz. Utilizou-se espaçamento de $0,40 \mathrm{~m}$ e densidade de semeadura de 70 sementes viáveis por metro. A semeadura foi realizada na segunda quinzena de outubro, dos anos agrícolas 2001/2002 e 2002/2003. Cada parcela foi constituída por quatro linhas de seis metros de comprimento, com duas linhas centrais, consideradas como área útil, tendo-se deixado 0,5 m em cada extremidade. As irrigações foram realizadas por meio de um sistema pivô central, em turnos e quantidades de água de acordo com a necessidade da cultura. 
As adubações de semeadura com $\mathrm{P}, \mathrm{K}$ e micronutrientes basearam-se na análise do solo e na Tabela de recomendação de adubação para a cultura do arroz irrigado, para o Estado de São Paulo, conforme Raij et al. (1997), com uso de superfosfato simples, cloreto de potássio, sulfato de zinco e bórax. Foram aplicados $30 \mathrm{~kg} \mathrm{ha}^{-1}$ de $\mathrm{N}$ (uréia), com os outros nutrientes, no sulco de semeadura (exceto no tratamento zero de $\mathrm{N}$ ), e o restante foi aplicado em cobertura.

O delineamento estatístico utilizado foi o de blocos ao acaso, em um esquema fatorial $2 \times 4 \times 3$, com 24 tratamentos constituídos pela combinação de duas cultivares de arroz (IAC 201 e IAC 202), quatro doses de $\mathrm{N}$ em cobertura $\left(0,50,100\right.$ e $\left.150 \mathrm{~kg} \mathrm{ha}^{-1}\right)$ e três doses de regulador de crescimento cloreto de clormequat $\left(0,1\right.$ e $\left.2 \mathrm{~L} \mathrm{ha}^{-1}\right)$, com quatro repetições. A aplicação do regulador de crescimento foi parcelada aos 20 e 30 dias após a emergência das plântulas de arroz (perfilhamento). Na adubação nitrogenada de cobertura, utilizou-se como fonte a uréia, aplicada no estádio de seis a oito folhas (diferenciação floral), e após a aplicação, foi efetuada irrigação com a finalidade de minimizar as perdas de $\mathrm{N}$ por volatilização. As plantas foram pulverizadas com tebuconazole (150 $\mathrm{g} \mathrm{ha}^{-1}$ de i.a.) contra doenças fúngicas como brusone, mancha-parda e mancha-estreita, que ocorrem normalmente na região.

Foram realizadas as seguintes avaliações: altura de plantas, obtida pela medida de dez plantas ao acaso, por parcela, tendo-se considerado a distância entre a superfície do solo e o ápice da panícula, por ocasião da colheita; grau de acamamento, obtido por meio de observações visuais, na fase de maturação, com uso da seguinte escala de notas: 1 , para 0 a $5 \%$; , para 6 a $25 \%$; 3, para 26 a 50\%; 4, para 51 a $75 \%$; e 5, para maior que $75 \%$ de plantas acamadas; número de panículas por metro quadrado, contando-se as panículas em $1 \mathrm{~m}^{2}$ da área útil da parcela; comprimento da panícula, com a distância medida a partir do nó basal até a extremidade superior $(\mathrm{cm})$; espiguetas por panícula, tendo sido coletadas dez panículas dentro da área útil da parcela; porcentagem de fertilidade das espiguetas, obtido por meio do número de espiguetas granadas e do número total de espiguetas, determinado com a coleta de dez panículas ao acaso, por parcela: IF = 100(número de espiguetas granadas/número total de espiguetas); massa de 100 grãos, determinada em coleta ao acaso, e pesagem de duas amostras de 100 grãos de cada parcela (13\% base úmida); e produtividade de grãos, obtida com a colheita de duas linhas centrais de cada parcela, seguida de trilhagem. Os grãos obtidos foram pesados, e os dados transformados em $\mathrm{kg} \mathrm{ha}^{-1}$ (13\% base úmida).

O Sanest (Zonta et al., 1987) foi utilizado para a realização das análises de variância. O teste de Tukey a 5\% de probabilidade foi usado para comparar as médias das cultivares de arroz. Para as doses de $\mathrm{N}$ e de regulador de crescimento, aplicaram-se análises de regressão, para se verificar se houve ou não ajuste aos dados obtidos.

\section{Resultados e Discussão}

Para altura de plantas, observa-se que houve efeito significativo para cultivares, nos dois anos de cultivo (2001/ 2002 e 2002/2003), em que a IAC 201 apresentou maiores valores que a IAC 202 (Tabela 1).

Noprimeiro ano (2001/2002), houve efeito significativo para doses de $\mathrm{N}$, em que os dados se ajustaram a uma equação linear crescente. Arf (1993), em experimento realizado na mesma região, também observou aumento na altura de planta com o fornecimento de doses crescentes de N. Fageria \& Wilcox (1977) observaram que a maior altura foi obtida com a dose de $150 \mathrm{~kg} \mathrm{ha}^{-1}$ de N, e Lopes et al. (1996) verificaram incremento na estatura das plantas com o aumento das doses de N. No entanto, Mauad et al. (2003) verificaram

Tabela 1. Altura de planta, número de panículas e comprimento da panícula de arroz irrigado por aspersão, em resposta a doses de nitrogênio e ao redutor de crescimento cloreto de clormequat, nas safras 2001/2002 e 2002/2003(1).

\begin{tabular}{|c|c|c|c|c|c|c|}
\hline \multirow[t]{3}{*}{ Tratamento } & \multicolumn{2}{|c|}{$\begin{array}{l}\text { Altura de plantas } \\
(\mathrm{cm})\end{array}$} & \multicolumn{2}{|c|}{ Panículas $\left(\mathrm{n}^{\circ} \mathrm{m}^{-2}\right)$} & \multicolumn{2}{|c|}{$\begin{array}{c}\text { Comprimento } \\
\text { de panícula }(\mathrm{cm})\end{array}$} \\
\hline & $2001 /$ & $2002 /$ & $2001 /$ & $2002 /$ & $2001 /$ & $2002 /$ \\
\hline & 2002 & 2003 & 2002 & 2003 & 2002 & 2003 \\
\hline \multicolumn{7}{|l|}{ Cultivares } \\
\hline IAC 201 & $109 \mathrm{a}$ & $87 \mathrm{a}$ & $182 b$ & $150^{\mathrm{ns}}$ & $25,0^{\mathrm{ns}}$ & $27,2 b$ \\
\hline IAC 202 & $104 \mathrm{~b}$ & $82 b$ & $239 a$ & $154^{\mathrm{ns}}$ & $24,8^{\text {ns }}$ & $28,3 \mathrm{a}$ \\
\hline \multicolumn{7}{|l|}{$\overline{N\left(\mathrm{~kg} \mathrm{ha}^{-1}\right)}$} \\
\hline 0 & 104 & 83 & 201 & 157 & 23,9 & 27,1 \\
\hline 50 & 106 & 84 & 218 & 147 & 24,6 & 27,4 \\
\hline 100 & 107 & 85 & 204 & 160 & 25,8 & 27,9 \\
\hline 150 & 109 & 86 & 218 & 143 & 25,2 & 28,4 \\
\hline \multicolumn{7}{|c|}{ Regulador $\left(\mathrm{L} \mathrm{ha}^{-1}\right)$} \\
\hline 0 & 108 & 83 & 217 & 156 & 25,5 & 27,8 \\
\hline 1 & 107 & 86 & 195 & 149 & 24,7 & 27,6 \\
\hline 2 & 106 & 84 & 221 & 151 & 24,4 & 27,7 \\
\hline $\mathrm{CV}(\%)$ & 6,88 & 5,40 & 23,40 & 23,28 & 6,4 & 3,8 \\
\hline
\end{tabular}

(1)Médias seguidas de letras iguais, na mesma coluna, não diferem entre si pelo teste de Tukey, a 5\% de probabilidade; equação de regressão e coeficiente de determinação para altura de planta e doses de N, em 2001/2002: $\mathrm{y}=104,1000+0,0300 \mathrm{x}, \mathrm{R}^{2}=0,9846$; equações de regressão e coeficientes de determinação para comprimento de panícula e doses de $\mathrm{N}$, em 2001/2002 e 2002/2003, respectivamente: $y=24,1530+0,0103 x$, $\mathrm{R}^{2}=0,6726 ; \mathrm{y}=27,0456+0,0093 \mathrm{x}, \mathrm{R}^{2}=0,9890$. ${ }^{\text {ns Não-significativo. }}$ 
uma redução na altura de planta, quando a dose de $\mathrm{N}$ foi aumentada. Isto mostra que o efeito do $\mathrm{N}$ na altura da planta depende de outros fatores como luminosidade, temperatura e umidade.

Para as doses de regulador, não houve ajuste às funções matemáticas testadas. O efeito do regulador cloreto de mepiquat foi avaliado na cultura do algodão por Lamas et al. (2000), que observaram redução na altura das plantas com o aumento da dose do regulador. Furlani Júnior et al. (2003), ao testar doses de N e aplicação gradativa do mesmo regulador de crescimento no algodoeiro, aliaram a dose ao estádio fenológico e verificaram efeito positivo na inibição de crescimento em até $11,4 \%$. Na cultura do trigo, Zagonel et al. (2002) verificaram que o regulador de crescimento trinexapac-etil promoveu uma redução na estatura das plantas, pela diminuição do comprimento dos entrenós, o que resultou em plantas mais compactas, com melhor direcionamento dos fotoassimilados para a produção de grãos. Outros estudos devem ser realizados, para avaliar doses, épocas de aplicação e outros reguladores, visandose à diminuição do porte da cultura, sem causar diminuição na produtividade e na qualidade de grãos.

$\mathrm{Na}$ avaliação do grau de acamamento, todos os tratamentos tiveram nota 1 , ou seja, até $5 \%$ de plantas acamadas na época da colheita. A cultivar IAC 201, tida como de fácil acamamento, não superou os $5 \%$ mencionados, mesmo nos tratamentos em que a dose aplicada de $\mathrm{N}$ foi alta.

No que se refere ao número de panículas, no primeiro ano agrícola 2001/2002, a cultivar IAC 202 apresentou maior média que a IAC 201 e, no segundo ano (2002/ 2003), não houve diferença entre as cultivares (Tabela 1). Para as doses de $\mathrm{N}$ e regulador de crescimento, não houve ajuste às funções matemáticas testadas nos respectivos anos agrícolas.

Meira et al. (2005) estudaram doses de 0 a $150 \mathrm{~kg} \mathrm{ha}^{-1}$ de N, nas cultivares IAC 201 e IAC 202, e não verificaram diferenças significativas, o que indica que as cultivares apresentaram capacidade de perfilhamento semelhante. Neves et al. (2004) estudaram doses de N nos cultivares Carajás e IAC 202 e, também, não verificaram efeito das doses de $\mathrm{N}$ no número de panículas.

Porém, Stone \& Silva (1998) e Mauad et al. (2003) verificaram menor valor para essa característica, na ausência de $\mathrm{N}$, já que este nutriente estimula o perfilhamento e aumenta o número de panículas por área.
Portanto, essa variação é um indicativo que as condições de manejo, cultivar, época, local e outros influenciam na resposta da cultura à adubação nitrogenada.

Como o número de panículas é definido durante o período de germinação, até dez dias depois que o primórdio da panícula é visível (Fornasieri Filho \& Fornasieri, 1993), é possível que as diferenças de resultados, nos vários trabalhos citados, têm como fator principal a antecipação ou não na aplicação do $\mathrm{N}$ em cobertura.

O regulador de crescimento não influenciou o número de panículas. A primeira aplicação, no início do perfilhamento, visava à emissão de maior número de perfilhos, já que este normalmente se correlaciona com a produtividade da cultura, mas tal emissão não ocorreu.

Para comprimento da panícula, observa-se que no primeiro ano agrícola (2001/2002) não houve diferença significativa entre as cultivares, mas a cultivar IAC 202 propiciou panículas maiores no segundo ano (Tabela 1). As doses de $\mathrm{N}$, nos dois anos agrícolas, aumentaram linearmente tal avaliação. Isto pode ser interessante, do ponto de vista econômico, já que a planta pode produzir mais grãos. O regulador de crescimento não influenciou essa avaliação.

Quanto ao número de espiguetas por panícula, as cultivares não apresentaram diferenças significativas, nos dois anos agrícolas. As doses de $\mathrm{N}$ propiciaram aumentos lineares nesta avaliação (Tabela 2). O número total de espiguetas é influenciado por fatores genéticos e condições externas vigentes, durante a fase reprodutiva, mais precisamente do início da fase reprodutiva até os cinco dias que antecedem o florescimento. Isto mostra a necessidade de se utilizar o $\mathrm{N}$, já que o número de espiguetas por panícula é extremamente importante na produtividade da cultura.

Coelho (1976) também verificou aumentos no número de espiguetas por panículas, assim como no número de grãos, com a aplicação do N. No entanto, Santos et al. (1986) aplicaram o $\mathrm{N}$ na semeadura e verificaram redução no número de grãos por panícula, e Stone et al. (1979) não verificaram efeito no número de grãos por panícula, quando doses de $\mathrm{N}$ foram testadas.

As diferenças de respostas encontradas nos trabalhos relacionaram-se às cultivares estudadas, ao clima, e ao manejo da água e do solo. 
Para as doses de regulador houve ajuste à equação linear decrescente, no primeiro ano, e crescente no segundo ano, o que mostra a interação existente entre o regulador de crescimento e as condições climáticas. Observa-se que no primeiro ano, as plantas foram maiores, apresentaram melhor perfilhamento, maior índice de fertilidade e maior produtividade de grãos.

Para a porcentagem de fertilidade das espiguetas, observase que tanto na safra 2001/2002 quanto na safra 2002/2003, a cultivar IAC 201 apresentou maior média, em relação a IAC 202 (Tabela 2). A fertilidade das espiguetas diminuiu linearmente com as doses de N, nos dois anos agrícolas. Ela expressa a porcentagem das espiguetas que se tornaram grãos. Este componente do rendimento é dependente da translocação de carboidratos, e é influenciado pelo ambiente, assim como níveis excessivos de fertilizantes nitrogenados.

Mauad et al. (2003) verificaram que a adubação nitrogenada proporcionou modificações na fertilidade das espiguetas. Este comportamento poderia ser relacionado ao fato de que no estágio vegetativo havia uma grande

Tabela 2. Número de espiguetas por panícula e porcentagem de fertilidade das espiguetas de arroz irrigado por aspersão, em resposta a doses de nitrogênio e ao regulador de crescimento cloreto de clormequat, nas safras 2001/2002 e 2002/ $2003^{(1)}$.

\begin{tabular}{|c|c|c|c|c|}
\hline \multirow[t]{2}{*}{ Tratamento } & \multicolumn{2}{|c|}{$\begin{array}{l}\text { Espiguetas (n-o por } \\
\text { panícula) }\end{array}$} & \multicolumn{2}{|c|}{$\begin{array}{c}\text { Fertilidade de espiguetas } \\
(\%)\end{array}$} \\
\hline & $2001 / 2002$ & $2002 / 2003$ & $2001 / 2002$ & $2002 / 2003$ \\
\hline \multicolumn{5}{|l|}{ Cultivares } \\
\hline IAC 201 & $184,3^{\text {ns }}$ & $210,5^{\mathrm{ns}}$ & $87,3 \mathrm{a}$ & $78,7 \mathrm{a}$ \\
\hline IAC 202 & $191,2^{\mathrm{ns}}$ & $224,2^{\text {ns }}$ & $82,6 b$ & $68,4 \mathrm{~b}$ \\
\hline \multicolumn{5}{|l|}{$\mathrm{N}\left(\mathrm{kg} \mathrm{ha}^{-1}\right)$} \\
\hline 0 & 176,7 & 208,1 & 86,7 & 78,0 \\
\hline 50 & 185,1 & 207,0 & 85,2 & 74,4 \\
\hline 100 & 198,3 & 220,2 & 83,8 & 70,1 \\
\hline 150 & 190,8 & 234,1 & 84,1 & 71,8 \\
\hline \multicolumn{5}{|c|}{ Regulador $\left(\mathrm{L} \mathrm{ha}^{-1}\right)$} \\
\hline 0 & 198,9 & 211,5 & 85,1 & 72,3 \\
\hline 1 & 191,7 & 210,4 & 84,7 & 73,2 \\
\hline 2 & 172,6 & 230,1 & 85,1 & 75,3 \\
\hline $\mathrm{CV}(\%)$ & 18,65 & 16,8 & 4,45 & 12,5 \\
\hline
\end{tabular}

(1)Médias seguidas de letras iguais, na mesma coluna, não diferem entre si pelo teste de Tukey, a 5\% de probabilidade; equações de regressão e coeficientes de determinação para número de espiguetas por panícula e doses de N, em 2001/2002 e 2002/2003, respectivamente: $y=179,4010$ $+0,1116 x, R^{2}=0,6182 ; y=203,7033+0,1823 x, R^{2}=0,8635$; equações de regressão e coeficientes de determinação para número de espiguetas por panícula e doses de regulador de crescimento, em 2001/2002 e 2002/2003, respectivamente: $\mathrm{y}=200,9218-13,1350 x, \mathrm{R}^{2}=0,9371$; $y=208,0896+9,2906 x, R^{2}=0,7066$; equações de regressão e coeficientes de determinação para porcentagem de fertilidade de espiguetas e doses de N, em 2001/2002 e 2002/2003, respectivamente: y=86,3681 - 0,0184x, $\mathrm{R}^{2}=0,8280 ; \mathrm{y}=77,1000-0,0463 \mathrm{x}, \mathrm{R}^{2}=0,7454$. ${ }^{\text {ns Não-significativo. }}$ quantidade de $\mathrm{N}$ disponível para a planta, que aumentou o número das panículas. O fato das doses de $\mathrm{N}$ diminuírem a fertilidade das espiguetas deve estar relacionado ao fato de o elemento proporcionar maior número de espiguetas por panícula. O regulador de crescimento não influenciou essa avaliação.

Quanto à massa de 100 grãos, verifica-se que a cultivar IAC 201 apresentou média superior ao IAC 202, nos dois anos agrícolas (2001/2002 e 2002/2003). Os níveis crescentes de $\mathrm{N}$ reduziram a massa de 100 grãos(Tabela 3). Houve ajuste das doses de $\mathrm{N}$ à regressão linear decrescente. A massa de 100 grãos é uma característica estável da variedade e depende do tamanho do grão. Ao trabalhar com doses de $\mathrm{N}$ na cultura de arroz, Stone et al. (1979) não verificaram aumento na massa de 100 grãos, e Santos et al. (1986) verificaram decréscimo. O regulador de crescimento também não exerceu nenhum efeito nessa avaliação.

Para a produtividade de grãos, a IAC 202 apresentou maior média (6.615 kg ha-1) que a IAC $201\left(6.065 \mathrm{~kg} \mathrm{ha}^{-1}\right)$, no primeiro ano agrícola, e com $5.155 \mathrm{~kg} \mathrm{ha}^{-1}$ (IAC 202) e $4.791 \mathrm{~kg} \mathrm{ha}^{-1}$ (IAC 201) no segundo ano. As doses de $\mathrm{N}$ se ajustaram à equação linear crescente (em 2001/2002), com

Tabela 3. Massa de 100 grãos e produtividade de grãos de arroz irrigado por aspersão, em resposta a doses de nitrogênio e ao regulador de crescimento cloreto de clormequat, nas safras 2001/2002 e 2002/2003(1).

\begin{tabular}{cccccc}
\hline Tratamento & \multicolumn{2}{c}{$\begin{array}{c}\text { Massa de 100 } \\
\text { grãos }(\mathrm{g})\end{array}$} & & \multicolumn{2}{c}{$\begin{array}{c}\text { Produtividade de grãos } \\
\left(\mathrm{kg} \mathrm{ha}^{-1}\right)\end{array}$} \\
\cline { 2 - 3 } \cline { 5 - 6 } & $2001 / 2002$ & $2002 / 2003$ & & $2001 / 2002$ & $2002 / 2003$ \\
\hline Cultivares & & & & & \\
IAC 201 & $2,4 \mathrm{a}$ & $2,5 \mathrm{a}$ & & $6.065 \mathrm{~b}$ & $4.791 \mathrm{~b}$ \\
$\mathrm{IAC} \mathrm{202}$ & $2,3 \mathrm{~b}$ & $2,1 \mathrm{~b}$ & & $6.615 \mathrm{a}$ & $5.155 \mathrm{a}$ \\
\hline $\mathrm{N}\left(\mathrm{kg} \mathrm{ha}^{-1}\right)$ & & & & & \\
0 & 2,3 & 2,4 & & 6.037 & 4.009 \\
50 & 2,3 & 2,3 & & 6.196 & 5.350 \\
100 & 2,3 & 2,2 & & 6.432 & 5.290 \\
150 & 2,3 & 2,2 & & 6.695 & 5.242 \\
\hline Regulador $\left(\mathrm{L} \mathrm{ha}^{-1}\right)$ & & & & \\
0 & 2,3 & 2,3 & & 6.349 & 4.892 \\
1 & 2,3 & 2,3 & & 6.362 & 5.010 \\
2 & 2,3 & 2,3 & & 6.309 & 5.016 \\
\hline $\mathrm{CV}(\%)$ & 3,81 & 8,06 & 18,53 & 15,78 \\
\hline
\end{tabular}

(1)Médias seguidas de letras iguais, na mesma coluna, não diferem entre si pelo teste de Tukey, a 5\% de probabilidade; equações de regressão e coeficientes de determinação para massa de 100 grãos e doses de $\mathrm{N}$, em 2001/2002 e 2002/2003, respectivamente: y = 2,3495 - 0,0003x, $\mathrm{R}^{2}=0,5729 ; \mathrm{y}=2,3962-0,0015 \mathrm{x}, \mathrm{R}^{2}=0,9542$; equações de regressão e coeficientes de determinação para produtividade de grãos e doses de $\mathrm{N}$, em 2001/2002 e 2002/2003, respectivamente: $\mathrm{y}=6008,8910+$ $4,4230 x, R^{2}=0,9885 ; y=4079,9479+28,1094 x-0,1388 x^{2}$, $\mathrm{R}^{2}=0,9198$. ns Não-significativo. 
a dose econômica alcançada com à aplicação de $100 \mathrm{~kg} \mathrm{ha}^{-1}$ de $\mathrm{N}$, e à equação quadrática, em que a dose de $100 \mathrm{~kg} \mathrm{ha}^{-1}$ de $\mathrm{N}$ foi a que proporcionou a produtividade máxima (5.500 kg ha-1), no segundo ano. Dose esta superior à recomendada para o Estado de São Paulo (Raij et al., 1997).

No trabalho de Andrade \& Amorim Netto (1996), o aumento na produtividade, em razão da adubação nitrogenada ocorreu, em parte, graças ao aumento dos componentes de produção número de panículas e número de grãos por panícula.

Santos et al. (1986) e Andrade \& Amorim Neto (1996) verificaram aumento da produtividade de grãos em relação direta com o número de panículas por metro quadrado. Neves et al. (2004) verificaram que os tratamentos que receberam cobertura nitrogenada produziram mais que $4.000 \mathrm{~kg} \mathrm{ha}^{-1}$ de grãos, o que mostra a importância dessa prática na cultura do arroz, para obtenção de alta produtividade. Meira et al. (2005) também obtiveram aumento na produtividade, com o fornecimento de adubo nitrogenado, em que a dose de 90 kg ha-1 proporcionou a máxima produção, assim como Freitas et al. (2001) e Mariot et al. (2003). Entretanto, Arf (1993) ao estudar diferentes cultivares de arroz de sequeiro e quatro épocas de adubação nitrogenada, nas doses de $10 \mathrm{~kg} \mathrm{ha}^{-1}$ de $\mathrm{N}$ na semeadura, e $40 \mathrm{~kg} \mathrm{ha}^{-1}$ de $\mathrm{N}$ em cobertura, observou que a adubação nitrogenada não influenciou a produtividade, embora esta tenha superado $4.000 \mathrm{~kg} \mathrm{ha}^{-1}$.

Esses dados sugerem que o efeito da aplicação do $\mathrm{N}$ sobre a produtividade é variável e dependente de vários fatores (Fageria \& Wilcox, 1977). O regulador de crescimento não exerceu efeito na produtividade de grãos, uma vez que esta acompanhou o comprimento de panícula, não influenciada pelo regulador, e o número de espiguetas por panícula, a qual foi dependente do ano em estudo.

\section{Conclusões}

1. As doses de $\mathrm{N}$ aumentam o comprimento das panículas e a produtividade de grãos, e diminuem a fertilidade de espiguetas e a massa de 100 grãos.

2. A aplicação de regulador de crescimento não influencia a altura de plantas e a produtividade da cultura.

\section{Referências}

ANDRADE, W.E. de B.; AMORIM NETTO, S. Influência da adubação nitrogenada sobre o rendimento e outros parâmetros de duas cultivares de arroz irrigado na região norte fluminense. Ciência e Agrotecnologia, v.20, p.293-300, 1996.

ARF, O. Efeitos de densidade populacional e adubação nitrogenada sobre o comportamento de cultivares de arroz irrigado por aspersão. 1993. 63p. Tese (Livre Docência) Universidade Estadual Paulista, Ilha Solteira.

ARF, O.; RODRIGUES, R.A.F.; CRUSCIOL, C.A.C.; SÁ, M.E. de; BUZETTI, S. Soil management and nitrogen fertilization for sprinkler-irrigated upland rice cultivars. Scientia Agricola, v.60, p.345-352, 2003.

ARTECA, R.N. Plant growth substances: principles and applications. New York: Chapman \& Hall, 1995. 332p.

CAMPELO JÚNIOR, J.H. Avaliação da capacidade de extração da água do solo pelo arroz de sequeiro (Oryza sativa $\mathbf{L}$.) sob diferentes doses de nitrogênio. 1985. 127p. Tese (Doutorado) Escola Superior de Agricultura Luiz de Queiroz, Piracicaba.

COELHO, M.B. Efeito da água disponível no solo e de níveis de nitrogênio sobre duas variedades de arroz. 1976. 42p. Dissertação (Mestrado) - Universidade Federal de Viçosa, Viçosa.

DAVIES, P.J. Plant hormones: physiology, biochemistry, and molecular biology. $2^{\text {nd }}$ ed. Dordrecht: Kluwer Academic, 1995. 833p.

EMBRAPA. Centro Nacional de Pesquisa de Solos (Rio de Janeiro, RJ). Sistema brasileiro de classificação de solos. Brasília: Embrapa-SPI, 1999. 412p.

FAO. Statistical database. Disponível em: <http:// www.safrasecifras.com.br/agropecuaria/artigos.html\#g>. Acesso em: 8 abr. 2004.

FAGERIA, N.K.; WILCOX, G.E. Influência de nitrogênio e fósforo no crescimento do arroz. Lavoura Arrozeira, v.30, p.24-28, 1977. FORNASIERI FILHO, D.; FORNASIERI, J.L. Manual da cultura do arroz. Jaboticabal: Funep, 1993. 221p.

FREITAS, J.G.; AZZINI, L.E.; CANTARELLA, H.; BASTOS, C.R.; CASTRO, L.H.S.M. de; GALLO, P.B.; FELÍCIO, J.C. Resposta de cultivares de arroz irrigado ao nitrogênio. Scientia Agricola, v.58, p.573-579, 2001.

FURLANI JUNIOR, E.; SILVA, N.M. da; CARVALHO, L.H.; BORTOLETTO, N.; SABINO, J.C.; BOLONHEZI, D. Modos de aplicação de regulador vegetal no algodoeiro, cultivar IAC-22, em diferentes densidades populacionais e níveis de nitrogênio em cobertura. Bragantia, v.62, p.227-233, 2003.

LAMAS, F.M. Estudo comparativo entre cloreto de mepiquat e cloreto de chlormequat aplicados no algodoeiro. Pesquisa Agropecuária Brasileira, v.36, p.265-272, 2001.

LAMAS, F.M.; ATAIDE, M.L.; BANZATTO, D.A. Reações do algodoeiro CNPA-ITA 90 ao cloreto de mepiquat. Pesquisa Agropecuária Brasileira, v.35, p.509-516, 2000.

LOPES, S.I.G.; LOPES, M.S.; MACEDO, V.R.M. Curva de resposta à aplicação de nitrogênio para quatro genótipos de arroz irrigado. Lavoura Arrozeira, v.49, p.3-6, 1996. 
MARIOT, C.H.P.; SILVA, P.R.F.; MENEZES, V.G.; TEICHMANN, L.L. Resposta de duas cultivares de arroz irrigado à densidade de semeadura e à adubação nitrogenada. Pesquisa Agropecuária Brasileira, v.38, p.233-241, 2003.

MAUAD, M.; CRUSCIOL, C.A.C.; GRASSI FILHO, H.; CORREAA, J.C. Nitrogen and silicon fertilization of upland rice. Scientia Agricola, v.60, p.761-765, 2003.

MEIRA, F.A.; BUZETTI, S.; FREITAS, J.G.; ARF, O.; SÁ, M.E. de. Resposta de dois cultivares de arroz à adubação nitrogenada e tratamento foliar com fungicidas. Acta Scientiarum, v.27, p.91-95, 2005.

NEVES, M.B.; BUZETTI, S.; ARF, O.; SÁ, M.E. de. Doses e épocas de aplicação de nitrogênio em dois cultivares de arroz com irrigação suplementar. Acta Scientiarum, v.26, p.429-435, 2004.

RADEMACHER, W. Growth retardants: effects on gibberellin biosynthesis and other metabolic pathways. Annual Review of Plant Physiology and Plant Molecular Biology, v.51, p.501-531, 2000.

RAIJ, B. van; CANTARELLA, H.; QUAGGIO, J.A.; FURLANI, A.M.C. (Ed.). Recomendações de adubação e calagem para o Estado de São Paulo. 2.ed. Campinas: Instituto Agronômico/ Fundação IAC, 1997. 285p. (Boletim técnico, 100).

RAIJ, B. van; QUAGGIO, J.A. Métodos de análise de solo para fins de fertilidade. Campinas: Instituto Agronômico, 1983. 31p. (Boletim técnico, 81).
SANTOS, A.B.; PRABHU, A.S.; AQUINO, A.R.L.; CARVALHO, J.R.T. Épocas, modos de aplicação e níveis de nitrogênio sobre brusone e produção de arroz de sequeiro. Pesquisa Agropecuária Brasileira, v.21, p.679-707, 1986.

STONE, L.F.; OLIVEIRA, A.B.; STEINNETZ, S. Deficiência hídrica e resposta de cultivares de arroz de sequeiro ao nitrogênio. Pesquisa Agropecuária Brasileira, v.14, p.295-301, 1979.

STONE, L.F.; SILVA, J.G. Resposta do arroz de sequeiro à profundidade de aração, adubação nitrogenada e condições hídricas do solo. Pesquisa Agropecuária Brasileira, v.33, p.891-897, 1998.

STONE, L.F.; SILVEIRA, P.M. da; MOREIRA, J.A.A.; YOKOYAMA, L.P. Adubação nitrogenada em arroz sob irrigação suplementar por aspersão. Pesquisa Agropecuária Brasileira, v.34, p.929-932, 1999.

ZAGONEL, J.; VENANCIO, W.S.; KUNZ, R.P.; TANAMAT, H. Doses de nitrogênio e densidades de plantas com e sem um regulador de crescimento afetando o trigo, cultivar OR-1. Ciência Rural, v.32, p.25-29, 2002.

ZONTA, E.P.; MACHADO, A.A.; SILVEIRA JUNIOR, P. Sistema de análise estatística para microcomputadores: manual de utilização. Pelotas: Ufpel, 1987. 177p.

Recebido em 8 de fevereiro de 2006 e aprovado em 9 de outubro de 2006 